Adıyaman Üniversitesi Sağlık Bilimleri Dergisi, 2020;6(1):77-83

doi:10.30569.adiyamansaglik.673993

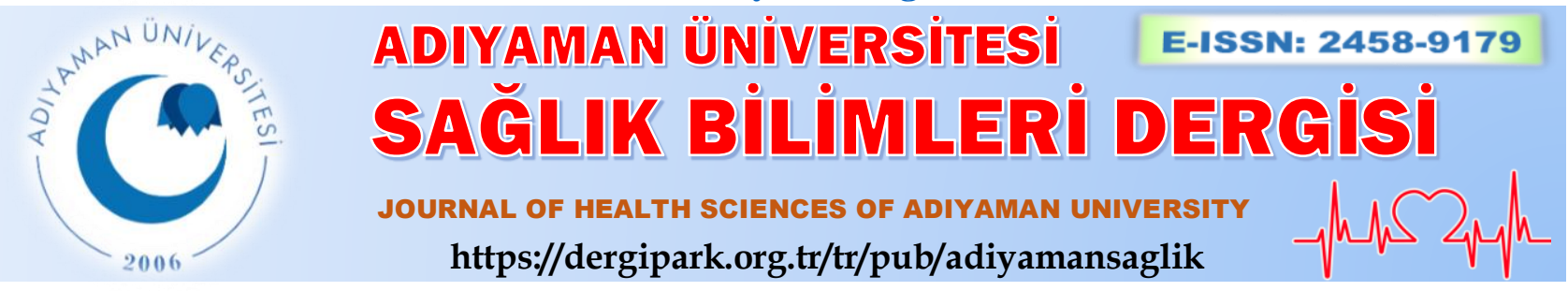

Özgün Araştırma/Research Article

\title{
Yaşı bakım personelinin yaşlılara karşı tutumlarının belirlenmesi: bakım sorunları ve müdahale önerileri
}

\section{Determination of elderly care personnel' attitudes towards the older adults: care problems and intervention suggestions}

\author{
Canan BİRIMOĞLU OKUYAN ${ }^{1 @(D), ~ F a t m a ~ K A R A S U ² ~}$ \\ ${ }^{1}$ Sakarya Uygulamalı Bilimler Üniversitesi, Sağlık Bilimleri Fakültesi, Hemşirelik Bölümü, 54400, Sakarya-Türkiye \\ ${ }^{2}$ Kilis 7 Aralık Üniversitesi, Yusuf Şerefoğlu Sağlık Bilimleri Fakültesi, Hemşirelik Bölümü, 79090, Kilis-Türkiye
}

Atıf gösterme/Cite this article as: Okuyan Birimoğlu C, Karasu F. Yaşlı bakım personelinin yaşlılara karşı tutumlarının belirlenmesi: bakım sorunları ve müdahale önerileri. ADYÜ Sağllk Bilimleri Derg. 2020;6(1):77-83. doi:10.30569.adiyamansaglik. 673993

\section{Öz}

Amaç: Araştırma, huzurevinde çalışan yaşlı bakım personelinin yaşlılara karşı tutum ve bakım sorunlarının belirlenmesi ve buna yönelik müdahale önerilerini sunmak amacıyla yapılmıştır.

Gereç ve Yöntem: Tanımlayıcı tipteki araştırmanın evrenini, bir huzurevinde çalışan yaşlı bakım personeli oluşturmuştur. Örneklem seçimine gidilmemiş olup araştırmaya katılmayı kabul eden 51 bakım personeli araştırmaya dâhil edilmiştir. Verilerin elde edilmesinde sosyo-demografik özellikler ve yaşlılık ile ilgili soruları içeren anket formu ve Kogan Yaşlılara Karşı Tutum Ölçeği kullanılmıştır.

Bulgular: Araştırmamıza katılan personelin \%49,0'ının kadın, \%60,8'inin aileden yaşıı bir birey ile yaşadığı saptanmıştır. Cinsiyeti kadın olan ve geniş aileye sahip yaşlı bakım personellerin Kogan Yaşlılara Karşı Tutum Ölçeği puan ortalamaları arasında istatistiksel olarak anlamlı bir fark olduğu belirlenmiştir $(p<0,05)$.

Sonuç: $\mathrm{Bu}$ çalışmada yaşlı bakım personelinin, yaşlılara karşı tutumlarının olumlu düzeyde olduğu saptanmıştır. Yaşlılara hizmet veren bakım personelinin olumlu tutumlarının geliştirilmesi ve sürekliliğinin sağlanması ile yaşlıya verilen bakım kalitesinin artırılması için kurumdaki oryantasyon programlarında yaşlı bakımı konularına yer verilmesi önemlidir.

Anahtar Kelimeler: Yaşlı; Tutum; Yaşlı Bakımı; Personel.

\begin{abstract}
Aim: The aim of this study was to determine the attitudes and care problems of the elderly care personnel working in the nursing home to the elderly and to provide intervention suggestions.

Materials and Methods: The population of this descriptive study consisted of elderly care personnel working in a nursing home. No sample selection was made and 51 care personnel who agreed to participate in the study were included in the study. Data were collected by using a questionnaire including sociodemographic characteristics and questions about old age and the Kogan Attitudes towards Older People scale.

Results: It was determined that $49.0 \%$ of the personnel who participated in our study lived with a woman and $60.8 \%$ lived with an elderly person from the family. It was determined that there was a statistically significant difference between the average of Kogan Elderly Attitude Scale for the elderly care staff, whose gender was female $(p<0.05)$.

Conclusion: In the present study, it was determined that the attitudes of elderly care personnel towards elderly people were positive. It is important to include elderly care topics in the orientation programs in the institution in order to develop and maintain the positive attitudes of the care staff serving the elderly, to increase the quality of care given to the elderly.
\end{abstract}

Keywords: Aged; Attitude; Elderly care; Personnel.

Yazışma Adresi/Address for Correspondence: Dr. Canan BİRIMOĞLU OKUYAN, Sakarya Uygulamalı Bilimler Üniversitesi, Sağlık Bilimleri Fakültesi, Hemşirelik Bölümü, 54400, Sakarya-Türkiye, E-mail: cananbirimoglu@ gmail.com

Geliş Tarihi/Received:13.01.2019 Kabul Tarihi/Accepted:14.03.2020 $\quad$ Yayım Tarihi/Published online:23.04.2020 


\section{Giriş}

Giderek artan yaşlı nüfus ile birlikte yaşlı bakımı ve yaşlıya bakım verenlerin yetersizliği, toplumda birçok sosyal sorunu beraberinde getirmektedir. Dünyada 60 yaş ve üzeri insan sayısının 2015 ve 2030 yıllar1 arasında $\% 56$ büyüyeceği ${ }^{1}$, Türkiye'nin 65 yaş üzeri nüfusunun 2050 yılına kadar $\% 20,8$ 'e yükseleceği tahmin edilmektedir. ${ }^{2}$ Dolayısıyla yaşlı nüfusun artmasıyla birlikte bağımlılık artmakta ve yaşlı bakımı zor, kapsamlı, pahalı ve ekip işbirliğiyle planlanması gereken önemli bir hizmet haline gelmektedir. ${ }^{3} \mathrm{Bu}$ hizmet, ailelerin geniş aileden çekirdek aileye dönüşmesi, eşlerin her ikisinin çalışması ve dolayısıyla doğurganlığın azalması, aile bireylerinin farklı kentlerde yaşamaları, sosyal hizmet alt yapılarının bulunmaması, ekonomik ve aile bağlarındaki değişiklikler gibi sorunlar nedeniyle ailede bakım sorunlarına yol açmakta ve bu durum da yaşl1, aile ve yakınlarını bakım kurumlarını seçmeye sevk etmektedir. ${ }^{4}$

Türkiye'de "formal" ve "informal" şekilde olan yaşlıların bakımı genellikle yaşıının kendi çocukları veya akraba desteği ile olmakta olup yaşı sağlığı hizmetleri huzurevleri, bakım ve rehabilitasyon merkezleri, evde bakım hizmetleri ve huzur evi projesi kapsamında faaliyet gösteren huzurevinde verilmektedir. ${ }^{5}$ Ak'1n 2016'da yaptığ 1 araştırmaya göre yaşlı bireylerin \%58,5'inin kendisi ve çocukları ile birlikte yaşadıkları belirlenmiştir. ${ }^{6}$ Kılıç ve Şelimen'in araştırmalarında yaşlıların daha çok yalnız $(\% 38,1)$ ve kendi evinde $(\% 22,5)$ yaşadıkları belirlenmiştir. ${ }^{7}$ Avrupa'da ise kurumsal bakım, evde bakım ve gündüz bakımı olarak verilmektedir. ${ }^{8}$ Yaşlı nüfusunun hızla artması yaşlı bakımında istihdam edilecek personel yetersizliği sorununu beraberinde getirmiştir. Bakım evlerinde çalışan hemşirelerin yetersiz kalması nedeniyle yaşlıların bakımını hazırlamak, yaşlının kişisel hijyenini sağlamak ve günlük yaşam aktivitelere mobilizasyonunu ve aktif katılımını teşvik etmek gibi sorumluluğa sahip olan ve yaşlı birey ile sıkça temas halinde olan bakım verenler yaşlılara bakım vermektedir. ${ }^{9}$
Yaşlı bireylerin farklı köken ve kültürden gelen insanlarla yaşamak zorunda oldukları ortam olan huzurevlerinde çalışan personelin tutumu yaşlıların ortama adaptasyonları ve huzurlarını sağlamak açısından çok önemlidir. Bakım personelinin yaşlilık konusundaki yetersiz bilgisi yaşlılara karşı olumsuz tutumlara neden olmakta ve yaşlilara yönelik bakımla ilgili olumlu tutumların gelişmesini ve verilen hizmetin verimliliğini azaltmaktadır. ${ }^{10,11}$

Arun ve Pamuk'ın bakım kurumlarında çalışan bakım personellerinin yaşlılara karşı tutumlarının ilkokul mezunu olanların üniversite mezunu olanlara göre daha olumsuz olduğunu belirtmiştir. ${ }^{12}$

Literatürde bakım vericilerin yaşlılara karşı tutum ve ayrımcılık düzeyleri ${ }^{13,14}$ ile ilgili birçok çalışma vardır. Ancak sadece yaşlılara bakım veren bakım personelinin yaşlılara ve yaşlı ayrımcılığına ilişkin tutum düzeylerini birlikte inceleyen çalışmalar sınırlı sayıdadır. ${ }^{12}$ Bu çalışmanın sonuçları, özellikle yaşlılara karşı istismar ve ihmalin önlenmesi, bakım verenlerin işe alınması ve yaşlıya verilen bakımın iyileștirilmesi ve geliştirilmesine önemli katkı sağlayacağını düşündürmektedir. Yaşlanan nüfus ve bakım verenlerin yaşl1lara karşı olumlu tutumu çok önemlidir. $\mathrm{Bu}$ sonuçtan hareketle çalışma yaşlı bakım personelinin yaşlılara karşı tutum ve bakım sorunlarının belirlenmesi ve buna yönelik müdahale önerileri sunmak amacıyla yapılmıştır.

\section{Araştırma Soruları}

1. Yaşlı bakım personelinin yaşlılara karşı tutumu nasıldir?

2. Yaşlı bakım personelinin YKTÖ ve alt boyutlarından aldığ 1 puan ortalamas 1 nedir?

3. YKTÖ puanları çalışma özelliklerine göre farklılaşmakta mıdır?

\section{Gereç ve Yöntem}

\section{Araştırmanın Evren Ve Örneklemi}

Tanımlayıcı tipte yapılan araştırmanın evrenini, bir huzurevinde çalışan 64 yaşlı bakım personeli oluşturmuş olup örneklem seçilmemiştir. Araştırmaya katılmayı kabul eden, veri toplama araçlarının uygulandığı 
günlerde ulaşılabilen yaşlı bakım personeli araştırmaya dâhil edilmiştir $(\mathrm{n}=51)$. Araştırmaya katılmayı kabul etmeyen, veri toplama araçlarının uygulandığ izinli olan, ulaşılamayan yaşlı bakım personeli araştırmaya dâhil edilmemiştir.

\section{Veri Toplama Araçları}

Literatür bilgileri doğrultusunda hazırlanan anket formu iki bölümden oluşmuştur. Birinci bölüm, kişilerin yaş, cinsiyet, memleket gibi sosyo-demografik özelliklerini belirlemeye yönelik kapalı uçlu sorulardan ${ }^{4,7,10}$, ikinci bölüm Yaşlı Ayrımcılığı Tutum Ölçeğinden oluşmuştur.

\section{Kogan Yaşlılara Karşı Tutum Ölçeği (YKTÖ)}

Nathan Kogan tarafindan 1961 yilında geliştirilen ölçek, bireylerin yaşlılara karş1 tutumlarını ölçmek amacıyla oluşturulmuş 34 maddeden oluşan ve altılı likert tipi bir ölçektir. ${ }^{15} \mathrm{Bu}$ çalışmada Kılıç ve Adıbelli tarafından geçerlik güvenirliği yapılarak uyarlanan formu kullanılmıştır. Ölçek toplam puanının yükselmesi bireyin yaşlılara karş1 pozitif tutumu olduğunu göstermektedir. ${ }^{16}$

\section{Verilerin Toplanması}

Veriler Kasım-Aralık 2019 tarihleri arasında araştırmaya katılacak bireylere araştırma ile ilgili bilgi verildikten sonra anket formu aracılığıyla araştırmacılar gözetiminde toplanmıştır. Anketin uygulaması toplamda 10-15 dakika sürmüştür.

\section{Verilerin Analizi}

Araştırmadan elde edilen veriler SPSS 22.0 (Statistical Package of SocialSciences) paket programı ile değerlendirilmiş olup normal dağılımın incelenmesi için KolmogorovSmirnov testi kullanılmıştır ve verilerin normal dağılım gösterdiği belirlenmiştir. Verilerin analizinde sayı, yüzdelik dağılımları, ortalama, standart sapma, t testi, tek yönlü varyans analizi (ANOVA) kullanılmıştır. Anlamlılık seviyesi olarak 0,05 alınmıştır.

\section{Araştırmanın Sınırlılıkları}

YKTÖ’nün geçerlik güvenirlik çalışmalarının üniversite öğrencileri ile yapılmış olması eğitim düzeyi düşük bir grubun ölçek maddelerini yeterli düzeyde anlamamasına ve Cronbach alfa katsayılarının geçerlilik ve güvenirlik yapılan çalışmalardan daha düşük değerde çıkmasına neden olmuştur. Bu durum araştırma için önemli bir sinırliliktır.

\section{Araştırmanın Etik Boyutu}

Araştırmanın yapılabilmesi için etik onay (Karar No: 27062019-02), kurum izni ve Aile, Çalışma ve Sosyal Hizmetler İl Müdürlüğü'nden gerekli izinler (Sayı: 94952863-605.01-E) alınmıştır. Araştırmanın amacı açıklanarak katılımcıların yazılı ve sözel onamları alındıktan sonra Helsinki bildirgesi kurallarına uygun olarak araştırma yürütülmüştür.

\section{Bulgular}

Araştırmaya katılan personellerin yaş ortalaması $41,78 \pm 6,97$, ailede yaşlı ile yaşama süresi $12,3 \pm 10,66$ y1l, huzur evinde çalışma süresi $8,43 \pm 4,45$ yıl, haftalık çalışma saati 47,62 $\pm 5,04$ bulunmuştur.

Araştırmaya katılan personellerin \%49,0'ının kadın, \%86,3'ünün evli, \%49,0'ının ilköğretim mezunu, \%78,4'ünün çekirdek aileye sahip, \%80,4'ünün kendilerini orta-yüksek gelir düzeyinde algıladığı, \%60,8'inin aileden bir yaşlı ile yaşadığ saptanmıştır. Yaşlı bakım personelinin cinsiyet ve ailede bir yaşlı ile yaşama durumuna göre Negatif ve Pozitif Tutum puan ortalamaları arasında istatistiksel olarak anlamlı bir fark olduğu saptanmıştır $(p<0,05)$. Cinsiyeti kadın olan, eğitim seviyesi lise ve üzeri olan ve geniş aileye sahip yaşlı bakım personellerin yaşlılara karşı pozitif tutum gösterdiği belirlenmiştir $(p<0,05)$ (Tablo 1$)$.

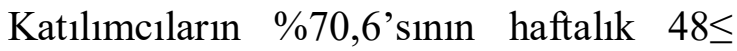
saat, \%60,8'inin 10< yıldır huzur evinde çalıştığ $1, \quad \% 94,1$ 'inin huzur evinde çalışmaktan memnun, \%64,7'sinin yaşlı bireylere bakım verirken sorun yaşadığ 1 , \%31,4'ünün yaşlı bireylere bakım verirken en sık yaşadıkları sorunun iletişim olduğu, \%52,9'unun yaşlı bakım ile ilgili eğitim alması gerektiği kanaatinde olduğu belirlenmiştir. Yaşlı bakım personelinin sertifika dışı eğitim alma durumuna göre Negatif tutum; yaşlı bakım ile ilgili eğitim 
alma gerekliliğine göre Pozitif tutum puan ortalamaları arasında istatistiksel olarak anlamlı bir fark olduğu saptanmıştır $(p<0,05)$. Katılımcıların yaşı bakımı ile ilgili eğitim almaları gereksinimine göre YKTÖ puan ortalamaları arasında istatistiksel olarak anlamlı bir fark olduğu saptanmıştır $(p<0,05)$ (Tablo 2).

Tablo 1. Yaşlı bakım personelinin sosyo-demografik özelliklerine göre YKTÖ, negatif tutum ve pozitif tutum puan ortalamaları $(\mathrm{n}=51)$.

\begin{tabular}{|c|c|c|c|c|c|c|c|}
\hline & \multirow[b]{2}{*}{ n $(\%)$} & \multicolumn{2}{|c|}{$\begin{array}{c}\text { Negatif Tutum Puan } \\
\text { Ortalamaları }\end{array}$} & \multicolumn{2}{|c|}{$\begin{array}{c}\text { Pozitif Tutum Puan } \\
\text { Ortalamaları }\end{array}$} & \multicolumn{2}{|c|}{ YKTÖ Puan Ortalamalar } \\
\hline & & $\mathbf{X} \pm \mathbf{S S}$ & Anlamlılık & $\mathbf{X} \pm \mathbf{S S}$ & Anlamlılık & $\mathbf{X} \pm \mathbf{S S}$ & Anlamlılık \\
\hline \multicolumn{8}{|l|}{ Cinsiyet } \\
\hline Kadın & $25(49,0)$ & $42,04 \pm 6,36$ & $t=-2,365$ & $48,04 \pm 9,30$ & $t=2,622$ & $90,08 \pm 12,80$ & $\mathrm{t}=0,589$ \\
\hline Erkek & $26(51,0)$ & $48,57 \pm 12,32$ & $p=0,022$ & $39,61 \pm 13,21$ & $p=0,012$ & $88,19 \pm 9,94$ & $p=0,558$ \\
\hline \multicolumn{8}{|l|}{ Medeni Durum } \\
\hline Evli & $44(86,3)$ & $46,09 \pm 10,64$ & $\mathrm{t}=1,225$ & $43,84 \pm 12,57$ & $\mathrm{t}=0,140$ & $89,93 \pm 11,19$ & $\mathrm{t}=1,291$ \\
\hline Bekar & $7(3,7)$ & $40,85 \pm 6,74$ & $p=0,216$ & $43,14 \pm 9,54$ & $p=0,889$ & $84,00 \pm 11,93$ & $p=0,203$ \\
\hline \multicolumn{8}{|l|}{ Eğitim Durumu } \\
\hline İlköğretim & $25(49,0)$ & $41,12 \pm 11,60$ & $\mathrm{t}=-1,548$ & $45,68 \pm 10,43$ & $\mathrm{t}=0,257$ & $86,64 \pm 11,11$ & $t=3,567$ \\
\hline$\geq$ Lise & $26(51,0)$ & $40,15 \pm 14,93$ & $p=0,128$ & $51,38 \pm 14,21$ & $p=0,778$ & $91,50 \pm 11,29$ & $p=0,032$ \\
\hline \multicolumn{8}{|l|}{ Aile Tipi } \\
\hline Çekirdek aile & $40(78,4)$ & $42,22 \pm 11,34$ & $\mathrm{t}=-1,180$ & $44,50 \pm 11,29$ & $\mathrm{t}=-2,121$ & $86,72 \pm 10,59$ & $\mathrm{t}=-2,929$ \\
\hline Geniş aile & $11(21,6)$ & $41,90 \pm 11,66$ & $p=0,244$ & $55,80 \pm 17,89$ & $p=0,045$ & $97,70 \pm 10,63$ & $p=0,005$ \\
\hline \multicolumn{8}{|c|}{ Algılanan Gelir Durumu } \\
\hline Düşük gelir & $10(19,6)$ & $45,70 \pm 14,25$ & $\mathrm{t}=0,111$ & $41,50 \pm 15,02$ & $t=-0,649$ & $87,20 \pm 11,97$ & $t=-0,591$ \\
\hline Orta-Yüksek gelir & $41(80,4)$ & $45,29 \pm 9,33$ & $p=0,912$ & $44,29 \pm 11,46$ & $p=0,519$ & $89,58 \pm 11,31$ & $p=0,557$ \\
\hline \multicolumn{8}{|c|}{ Aileden Bir Yaşlı İle Yaşama Durumu } \\
\hline Evet & $31(60,8)$ & $42,90 \pm 5,92$ & $t=-2,413$ & $46,38 \pm 9,06$ & $\mathrm{t}=2,282$ & $92,66 \pm 13,70$ & $\mathrm{t}=1,272$ \\
\hline Hayır & $20(39,2)$ & $49,84 \pm 14,18$ & $p=\mathbf{0 , 0 2 0}$ & $38,68 \pm 1487$ & $p=0,027$ & $86,93 \pm 10,16$ & $p=0,215$ \\
\hline Toplam & $51(100,0)$ & $45,37 \pm 10,30$ & & $43,74 \pm 12,12$ & & $89,11 \pm 11,36$ & \\
\hline
\end{tabular}

*YKTÖ: Kogan Yaşlılara Karşı Tutum Ölçeği

** $\mathrm{t}=\mathrm{t}$ testi, $\mathrm{F}=$ ANOVA testi.

Tablo 2. Yaşlı bakım personelinin mesleki özelliklerine göre YKTÖ, negatif tutum ve pozitif tutum puan ortalamaları $(n=51)$.

\begin{tabular}{|c|c|c|c|c|c|c|c|}
\hline & \multirow[b]{2}{*}{$\mathrm{n}(\%)$} & \multicolumn{2}{|c|}{$\begin{array}{c}\text { Negatif Tutum Puan } \\
\text { Ortalamaları }\end{array}$} & \multicolumn{2}{|c|}{$\begin{array}{c}\text { Pozitif Tutum Puan } \\
\text { Ortalamaları }\end{array}$} & \multicolumn{2}{|c|}{$\begin{array}{l}\text { YKTÖ Puan } \\
\text { Ortalamaları }\end{array}$} \\
\hline & & $\mathrm{X} \pm \mathrm{SS}$ & Anlamlılık & $\mathrm{X} \pm \mathrm{SS}$ & Anlamlılık & $\mathbf{X} \pm \mathbf{S S}$ & Anlamlılık \\
\hline \multicolumn{8}{|c|}{ Haftalık çalışma saati } \\
\hline $48 \leq$ saat & $36(70,6)$ & $45,33 \pm 10,03$ & $\mathrm{t}=-0,042$ & $43,38 \pm 11,91$ & $\mathrm{t}=-0,322$ & $88,72 \pm 12,28$ & $t=-0,382$ \\
\hline $48>$ saat & $15(29,4)$ & $45,46 \pm 11,30$ & $p=0,967$ & $44,60 \pm 12,99$ & $p=0,749$ & $90,06 \pm 9,08$ & $p=0,704$ \\
\hline \multicolumn{8}{|c|}{ Huzur evinde çalışma süresi } \\
\hline $10<$ y1l & $31(60,8)$ & $45,45 \pm 11,01$ & $\mathrm{t}=0,068$ & $44,19 \pm 13,10$ & $\mathrm{t}=0,326$ & $89,64 \pm 11,13$ & $\mathrm{t}=0,409$ \\
\hline $10 \geq \mathrm{y} 11$ & $20(39,2)$ & $45,25 \pm 9,38$ & $p=0,946$ & $43,05 \pm 10,71$ & $p=0,746$ & $88,30 \pm 11,95$ & $p=0,684$ \\
\hline \multicolumn{8}{|c|}{ Huzur evinde çalışmaktan memnun olma durumu } \\
\hline Memnun değilim & $3(5,9)$ & $35,66 \pm 9,45$ & $\mathrm{t}=-0,538$ & $50,00 \pm 13,11$ & $\mathrm{t}=0,196$ & $85,66 \pm 6,11$ & $\mathrm{t}=0,193$ \\
\hline Memnunum & $48(94,1)$ & $40,93 \pm 13,49$ & $p=0,593$ & $48,50 \pm 12,82$ & $p=0,845$ & $89,33 \pm 11,61$ & $p=0,825$ \\
\hline \multicolumn{8}{|c|}{ Yaşlı bireylere bakım verirken sorun yaşama durumu } \\
\hline Evet & $33(64,7)$ & $40,27 \pm 13,84$ & $\mathrm{t}=-0,256$ & $46,78 \pm 12,05$ & $\mathrm{t}=-1,382$ & $87,03 \pm 10,54$ & $\mathrm{t}=-1,817$ \\
\hline Hayır & $18(35,3)$ & $41,27 \pm 12,55$ & $p=0,799$ & $51,88 \pm 13,57$ & $p=0,173$ & $92,94 \pm 12,09$ & $p=0,075$ \\
\hline \multicolumn{8}{|c|}{ Yaşlı bireylere bakım verirken en sık yaşanılan sorunlar } \\
\hline İletişim & $16(31,4)$ & $46,93 \pm 11,88$ & & $40,75 \pm 12,19$ & & $87,68 \pm 13,95$ & \\
\hline Ziyaretçiler & $12(23,5)$ & $45,58 \pm 9,89$ & $\mathrm{~F}=0,225$ & $46,08 \pm 10,72$ & $\mathrm{~F}=1,404$ & $91,66 \pm 7,54$ & $\mathrm{~F}=1,131$ \\
\hline Ekip çalışması & $14(27,5)$ & $44,42 \pm 12,14$ & $p=0,879$ & $41,35 \pm 14,92$ & $p=0,253$ & $85,78 \pm 13,33$ & $p=0,346$ \\
\hline Bakım verme & $9(17,6)$ & $43,77 \pm 3,96$ & & $49,66 \pm 6,68$ & & $93,44 \pm 4,47$ & \\
\hline \multicolumn{8}{|c|}{ Sizce yaşı bakımı ile ilgili eğitim almanız gerekiyor mu? } \\
\hline Evet & $27(52,9)$ & $44,88 \pm 6,87$ & $t=-0,352$ & $47,51 \pm 9,12$ & $\mathrm{t}=2,475$ & $92,40 \pm 11,22$ & $\mathrm{t}=2,284$ \\
\hline Hayır & $24(47,1)$ & $45,91 \pm 13,30$ & $p=0,726$ & $39,50 \pm 13,78$ & $p=0,017$ & $85,41 \pm 10,54$ & $p=\mathbf{0 , 0 2 7}$ \\
\hline Toplam & $51(100,0)$ & $45,37 \pm 10,30$ & & $43,74 \pm 12,12$ & & $89,11 \pm 11,36$ & \\
\hline
\end{tabular}

*Sadece ailesinde bir yaşlı bireyle yaşayanlar alınmıştır. YKTÖ: Kogan Yaşlılara Karşı Tutum Ölçeği.

$* * \mathrm{t}=\mathrm{t}$ testi, $\mathrm{F}=$ ANOVA testi. 


\section{Tartışma}

Giderek artan yaşlı nüfusta özellikle huzurevinde yaşayan yaşlı bireyler ile daha fazla zaman geçiren bakım personellerinin yaşlanmaya ilişkin tutum düzeylerinin değerlendirilmesi/incelenmesi yaşlilara sunulan bakım kalitesinin artırılmas1 açısından anahtar roldedir. ${ }^{10} \mathrm{Bu}$ çalışma yaşlı bakım personelinin yaşlılara karş1 tutumlarının belirlenmesi ve bu anlamda müdahale önerileri sunmak amaciyla yapılmıştır. Ancak yaşlı bakım personelinin yaşlılara karşı tutumlarını belirlemeye yönelik sınırlı sayıda çalışmaya ulaşılmıştır. ${ }^{12,}{ }^{17} \mathrm{Bu}$ nedenle bu konuda farklı gruplar ile yapılmış çalışmalarla tartışılmıştır.

Çalışmada yaşlı bakım personelinin yaşlılara karşı genel olarak tutumlarının olumlu düzeyde olduğu belirlenmiştir. YKTÖ’ten en düşük 26, en yüksek 156 puan alınacağı göz önünde bulundurulduğunda, yaşlı bakım personelinin YKTÖ puan ortalaması $89,11 \pm 11,36$ olması pozitif yönde bir sonuçtur. Kılıç ve Adıbelli'nin yaptıkları çalışmada, huzur evinde çalışan hemşirelerin YKTÖ puan ortalamasını 98,08 \pm 13 ,13 olarak saptamıştır. ${ }^{16}$ Koç ve ark. yaptıkları bir çalışmada, klinik hemşirelerin yaşlılara ilişkin genel olarak tutumlarının olumlu yönde olduğu saptanmıştır. ${ }^{18}$ Doherty ve ark. araştırmasında, sağlık çalışanlarının yaşlılara karşı tutumlarının olumlu olduğu belirlenmiştir. ${ }^{19}$ Literatür sonuçları bu çalışma sonuçları ile benzerlik göstermektedir. Örneklem grubunun huzurevinden seçilmesi ve çalışanların yaşlılarla yakın ilişki içinde olması sonucu etkilediği görüşündeyiz. Ayrıca bu çalışmada yaşlıya yönelik pozitif tutum çıkması Türk aile yapısındaki geleneksel değerlerimiz ile büyük ölçüde ilişkili olabilir. Luchesi ve ark. yaptıkları çalışmada, yaşlı bakım personellerinin yaşlılara ilişkin tutumları nötr olarak belirlenmiştir. $^{20}$ Arani ve ark. yaptıkları araştırmada, çalışan hemşirelerin yaşlılara karşı tutumlarının genellikle olumsuz olduğunu saptamıştır. ${ }^{21}$ Asayesh ve ark. yaptıkları bir çalışmada, sağlık çalışanlarının yaşlılara ilişkin tutumlarını olumsuz olarak tespit etmiştir. ${ }^{22}$ Görüldüğ̈̈ gibi literatürde sağlık çalışanları ile yapılan çalışmalarda yaşlılara yönelik olumlu olduğu kadar olumsuz sonuçlarda mevcuttur. Bu çalışmada her ne kadar yaşlı bakım personelinin yaşlılara yönelik tutumları pozitif olsa da Negatif tutum puan ortalamas $45,37 \pm 10,30$ olarak saptanmıştır.

Çalışmada yaşlı bakım personellerinin cinsiyet durumu ile YKTÖ puan ortalamaları arasındaki fark istatistiksel olarak anlamlı bulunmamıştır. Fakat kadınların YKTÖ puan ortalamaları erkeklere göre daha yüksek olduğu görülmüştür. Yine kadınların Negatif tutum puan ortalamalarının erkeklere göre daha düşük ve pozitif tutum puan ortalamalarının erkeklere göre daha yüksek olduğu belirlenmiştir. Yapılan çalışmalarda cinsiyet durumları arasında yaşlılara yönelik tutum ile ilgili farklılığın bulunmadığ $1^{19}$ ve cinsiyet durumları arasında bir farklılığın bulunduğu çalışmalar mevcuttur. ${ }^{21}$ Yine literatürde yaşlılara yönelik kadınların erkeklere oranla daha pozitif tutum sergiledikleri bulunmuştur. ${ }^{23}$

Yaşlı bakım personellerinin eğitim düzeyi artıkça YKTÖ ve Pozitif tutum puan ortalamaları artarken Negatif tutum puan ortalamalarında azalma olduğu saptanmıştır. Literatürde yapılan çalışmalar, bakım personelinin eğitim düzeyi arttıkça yaşlıya karşı pozitif tutumun da arttığını göstermiştir. ${ }^{21,24}$

Çalışmada geniş aile yapısına sahip yaşlı bakım personellerinin YKTÖ puan ortalamasının daha yüksek olduğu görülmüştür. Yapılan bir çalışmada, geniş aileye sahip çalışanların YKTÖ puan ortalamasının çekirdek aileye sahip olanlara göre daha yüksek olduğu saptanmıştır. ${ }^{17}$ Son yıllarda hızlı sanayileşme ve kentleşmenin bir sonucu, ekonomik ve sosyal yapıdaki hızlı değişimlere bağlı olarak geniş aileler çekirdek aileye dönüşmüş buda yaşlılara karşı tutumu kısmen olumsuzda olsa etkilediğ $i$ kanaatindeyiz. Kendi ailesinde bir yaşlı ile yaşama durumu ile YKTÖ puan ortalamaları arasındaki fark istatistiksel olarak anlamlı bulunmamıştır. Ancak aileden bir yaşlı ile yaşayanların YKTÖ puan ortalamalarının daha yüksek, negatif tutumlarının düşük ve pozitif tutumlarının ise daha yüksek olduğu saptanmıştır. Söylemez ve ark. yaptıkları 
araştırmada, çalışanların kendi ailelerinde bir yaşı ile yaşayanların, yaşlılara karşı tutumlarının olumlu olduğu sonucuna ulaşılmıştır. ${ }^{25}$ Ailesinde yaşlı bir birey ile yaşayan bakım personelinin yaşlılık sürecine şahit olması, yaşlılığa dair her süreci gözlemleyebilmesi yaşlı bireye karşı iş hayatında da bu bilinçle hareket etmesini sağladığı düşünülmektedir.

Yaşlı bakım personelinin huzur evinde çalışma süresi ile YKTÖ puan ortalamaları arasındaki fark istatistiksel olarak anlaml bulunmazken çalışma yılı artıkça negatif tutumların düştüğü ve pozitif tutumların ise yükseldiği belirlenmiştir. Söylemez ve ark. yaptıkları araştırmada, çalışma süresi ile YKTÖ puan ortalamaları arasında istatistiksel olarak anlamlı bir fark olmadığ 1 saptanmıştır. ${ }^{25} \mathrm{Bu}$ bulgu literatürdeki diğer çalışmalar ile benzerlik göstermektedir. ${ }^{17,26}$

Araştırmamızda, yaşlı bakımı ile ilgili eğitim almak isteyenlerin YKTÖ puan ortalamaları yüksek, negatif tutumları düşük pozitif tutumları yüksek bulunmuştur. Yaşliya karş1 ya da yaşlılıkla ilgili önyargılar ve kalıp düşünceler bakımın kalitesini olumsuz etkilemektedir. $\mathrm{Bu}$ sebeple, özellikle bakım personellerinin yaşlıya yönelik olumlu tutumları pekiştiren olumsuz tutumları azaltan kurs, sertifika ve seminerlerin düzenlenmesi gerekmektedir.

\section{Sonuç}

$\mathrm{Bu}$ çalışmada yaşı bakım personelinin yaşlılara ilişkin tutumlarının olumlu düzeyde olduğu saptanmıştır. Yaşlı bakım personelinin eğitim durumu, aile tipi ve yaşlı bakımı ile ilgili eğitim almak isteyenler ile YKTÖ puan ortalamaları arasında anlamlı bir fark bulunmuştur. Yaşlilara hizmet veren bakım personelinin olumlu tutumlarının geliştirilmesi ve sürekliliği, yaşlıya verilen bakımı iyileştirilmesi ve geliştirilmesi için bakım personeli alımında kişilik profillerinin gözden geçirilmesi ayrıca kurumdaki oryantasyon programlarında yaşlı bakımı konularına da yer verilmesi yaşlıya verilen bakım kalitesinin ve değerin artırılması, yaşlı istismarlarının önlenmesi açısından önem arz etmektedir. Yapılacak araştırmanın daha büyük örneklem gruplarında yapılması özellikle nitel araştırmalar ile daha etkin çözüm önerileri sunulması önerilmektedir.

\section{Araştırmanın Etik Boyutu}

Araştırmanın yapılabilmesi için etik onay (Karar No: 27062019-02), kurum izni ve Aile, Çalışma ve Sosyal Hizmetler İl Müdürlüğü'nden gerekli izinler (Say1: 94952863-605.01-E) alınmıştır.

\section{Bilgilendirilmiş Onam}

\begin{tabular}{lccr}
\multicolumn{2}{c}{ Araştırmanın } & amacı & açlklanarak \\
katılımcıların & yazılı & ve sözel & onamları \\
alındıktan & sonra & Helsinki & bildirgesi \\
kurallarına & uygun & olarak & araştırma \\
yürütülmüştür. & & &
\end{tabular}

\section{Yazar Katkıları}

Araştırmanın hipotezini veya fikrini oluşturmak C.B.O, verilerin düzenlenmesi ve raporlanması C.B.O. ve F.K. katk1 sunmuşlardır.

\section{Teşekkürler}

$\mathrm{Bu}$ çalışmanın gerçekleşmesinde katkıları bulunan yaşı bakım personellerine teşekkür ederiz.

\section{Çıkar Çatışması}

Herhangi bir çıkar çatışması bulunmamaktadır.

\section{Araştırma Desteği}

Araştırmanın yapılması için herhangi bir destek alınmamıştır.

\section{Kaynaklar}

1. United Nations. Department of Economic and Social Affairs, Population Division (2015). World Population Ageing.. Erişim: http://

www.un.org/en/development/desa/population/publications/agei ng/WPA2015 Infochart.shtml Erişim Tarihi: 01.01.2020

2. TÜİK (Türkiye İstatistik Kurumu) (2013). Nüfus Projeksiyonlar1 2013-2075 Erișim: http://www.tuik.gov.tr/PreHaberBultenleri Erişim Tarihi: 25.12.2019.

3. Ecer S, Çamaş H. Formal ve informal bakım arasındaki ekonomik ilişki. Erişim: http://hdl.handle.net/11527/1245 Erișim Tarihi: 05.01.2020.

4. Akdemir N, Kapucu S, Özdemir L, Akkuş Y, Alparslan GB, Akyar İ. Huzurevi ve yaşlı bakım rehabilitasyon merkezlerinde çalışan hemşirelerin yaşadıkları bakım sorunları ve tükenmişlik düzeyleri. HEAD 2010; 12(3): 49-62.

5. Ministry of Family and Social Policies, Directorate of General Services for Persons with Disabilities and the Older persons. Erişim: http:// eyh.aile.gov.tr/kuruluslarimiz/kuruluslarimizyasli. Erişim Tarihi: 05.01.2020.

6. Ak M. Yaşlılık olgusu üzerine uygulamalı bir araştırma. Uluslararası Sosyal Araştırmalar Dergisi 2016;42(9): 1019-28. 
7. Kılıc Ü, Selimen D. Determination of the causes that force the elders to choose living in nursing homes. JAREN 2017;3(2): 73-82.

8. European Commission. Long-term care for the older persons provisions and providers in 33 European countries. (2012). Erişim: http:// ec.europa.eu/justice/gender-equality/files/older persons_care_en.pdf. Erişim Tarihi: 29.12.2019.

9. Announcement of National Occupational Standards. Announcement no: 2016/12. Erişim: http://www.resmigazete.gov.tr/eskiler/2016/10/20161025M1-314.pdf Erişim Tarihi: 29.12.2019.

10. Hanson RM. Is older persons care affected by nurse attitudes? A systematic review. Br J Nurs 2014; 23(4): 225-29.

11. Vefikuluçay Yılmaz D, Terzioğlu F. Development and psychometric evaluation of ageism attitude scale among the university students. Turk J Geriatr. 2011; 14(3): 259-68.

12. Arun Ö, Pamuk D. Kurumsal bakım sektöründe ageism: yaşlı bakım personelinin yaşlanma ve yaşlılığa ilişkin ayrımcı tutumlarının nedenleri ve müdahale önerileri. Mediterr J Soc Sci 2014;4(2): 19-33.

13. Nilsson A, Lindkvist M, Rasmussen BH, Edvardsson D. Staff attitudes towards older patients with cognitive impairment: need for improvements in acutecare. J Nurs Manag. 2012; 20(5): 640-47.

14. Coffey A, Whitehead N. Healthcare assistants' attitudes towards older people and their knowledge about ageing. Nurs. Older People 2015;27(1): 24-30.

15. Kogan N. Attitudes toward old people: the development of a scale and an examination of correlates. J. Abnorm. Psychol 1961; 62(1): 44-54.

16. Kılıç D, Adibelli D. The validity and reliability of Kogan's attitude towards old people scale in the Turkish society. Health 2011; 3(9): 602-8.

17. Ünalan D, Soyuer F, Elmalı F. Geriatri merkezi çalışanlarında yaşlı tutumunun değerlendirilmesi. Kafkas Tip Bilimleri Dergisi 2012;2(3):115-20.

18. Koç A, Öztaş D, Uysal N, Demircan Z, Erdem Ö, Sarı E. Klinik hemşirelerinin yaşlılara ilişkin düşünce ve tutumları. Ankara Med 2018; J (4): 500-7.

19. Doherty M, Mitchell EA, O'Neill S. Attitudes of Healthcare Workers towards Older People in a Rural Population: A Survey Using the Kogan Scale. Nurs Res Pract, 2011; 1-7.

20. Luchesi BM, Alexandre TD, de Oliveira NA, and et al. Factors associated with attitudes toward the elderly in a sample of elderly caregivers. Int Psychogeriatr 2016; 28(12): 2079-89.

21. Arani MM, Aazami S, Azami M, Borji M. Assessing attitudes toward elderly among nurses working in the city of Ilam. IJNSS 2017; 4: 311-13.

22. Asayesh H, Qorbani M, Parvaresh Masoud M, and et al. General practitioner attitude toward elders: using Kogan's attitudes questionnaire. Iran J Diabet Metab 2014; 13(6): 47986.

23. Adıbelli D, Kılıç D. Difficulties experienced by nurses in older patient care and their attitudes toward the older patient. Nurse Educ. Today 2013; 33: 1074-78.

24. Zehirlioğlu L, Yönt GH, Bayat E, Günay B. Hemşirelerin yaşlılara yönelik tutumları ve etkileyen faktörlerin belirlenmesi. Ylldırım Beyazıt Ü. Sağllk Bilimleri Fak. E-Dergisi 2015; 3(1): $10-18$.

25. Söylemez BA, Küçükgüçlü Ö, Akyol1 MA, Işık AT, Tekin N. Nursing homes nurses' attitudes toward older people and affectıng factors. Turk J Geriatr. 2018; 21(2): 271-78.

26. Aydın L, Yönet GH, Bayat E, Günay B. Hemşirelerin yaşlılara yönelik tutumları ve etkileyen faktörlerin belirlenmesi. Ylldırım Beyazıt Ü. Sağllk Bilimleri Fak. E-Dergisi 2016; 3(1): 10-18. 